\title{
A Note on Adenoma of the Labium.*
}

\author{
By Herbert Wilutamson, M.A., M.B.
}

My object in writing this note is to draw attention to a rare form of tumour of the labium, which is liable to be mistaken clinically for squamous-celled carcinoma.

Three years ago Dr. Champneys removed from the labium of a lady a small tumour which he regarded as an epithelioma. Microscopic examination showed that the growth was composed of glandular tissue, and that the ulceration of the surface was of a simple, not of a malignant, type. Dr. F. W. Andrewes pronounced the growth an adenoma; but, from the irregular appearance of some of the epithelial masses, I felt doubtful of the diagnosis, and thought the nodule might be a secondary deposit from a glandular cancer primary in some other part of the body. I have waited three years before reporting this case, and as the lady is still in good health, I am convinced that Dr. Andrewes was right, and that I was wrong. I am indebted to Dr. Champneys for the clinical notes of the case and for his kindness in investigating the afterhistory.

The patient was an unmarried lady of 62 ; for two and a half years she had suffered from a slight blood-stained vaginal discharge, and on one occasion, a year before consulting Dr. Champneys, there had been a sudden hæmorrhage, the quantity of blood lost being sufficient to soak one diaper. At the free edge of the right labium majus, near its anterior extremity and at some distance from the orifice of the right vulvo-vaginal gland duct, was a small growth equal in size to a split-pea. The growth was soft, pink in colour and ulcerated on the surface, and it bled very readily on touch. No enlargement of the inguinal glands could be detected.

The growth was removed in March, 1903, and at the present time (June, 1906) the patient's medical attendant reports that she is in good health and that no recurrence has taken place.

Microscopical examination. The tumour was attached to the labium by a broad base composed of delicate connective tissue, in which are embedded groups of large, thin-walled vessels. The base

* Read at a meeting of the Obstetrical Society of London, July 4th, 1906. 
of attachment and the proximal part of the tumour are covered by several layers of stratified squamous epithelium; the distal portion evidently possessed originally a similar epithelial covering; traces of it still remain, but, for the most part, it has been destroyed by a process of ulceration. The glandular tissue which constitutes the greater part of the growth is partially sub-divided into lobules by fibrous septa, and is marked off from the subjacent connective tissue by an incomplete capsule of concentrically arranged fibres.

The tumour consists of irregular glandular formations embedded in a delicate loose-meshed connective-tissue stroma. The gland acini and ducts vary in size and form; some are lined by a single layer of tall columnar cells resting upon a well-marked basement membrane and possessing a vesicular nucleus situate near the base of the cell; some of the acini are dilated and form cystic spaces. The whole growth, however, is not of this simple type; many of the lumina are lined by two or three layers, the deeper cells rounded, the more superficial columnar, but the basement membrane is still preserved intact. Some of the tubes show irregular branchings and anastomoses between the branches of adjacent acini; there are also present, embedded in the stroma, masses and solid columns of epithelial cells; these are for the most part sharply defined from the surrounding connective-tissue and possess characters similar to those of the cells which line the lumina. It was the presence of these irregular columns and masses which made me suspicious that the tumour was possibly of a malignant nature. The stroma at the more superficial part of the tumour is infiltrated with inflammatory cells.

I have succeeded in finding records of three similar growths; two cases are reported by Pick and one by Schickele. As far as I am aware, no description of these tumours is to be found in English literature.

CASE I. (L. Pick). An unmarried woman, 40 years of age, had noticed for the last two years a small tumour on the posterior part of the left labium majus. Shortly before she sought advice two others had appeared, one on the right labium and the third on the left labium.

On examination a small red-coloured tumour the size of a bean was seen on the inner aspect of the right labium majus, near its free border, at the level of the urethral orifice; a second, somewhat larger, was situated on the left labium, close to the opening of Bartholin's duct, and near to this was a third smaller one. All the 


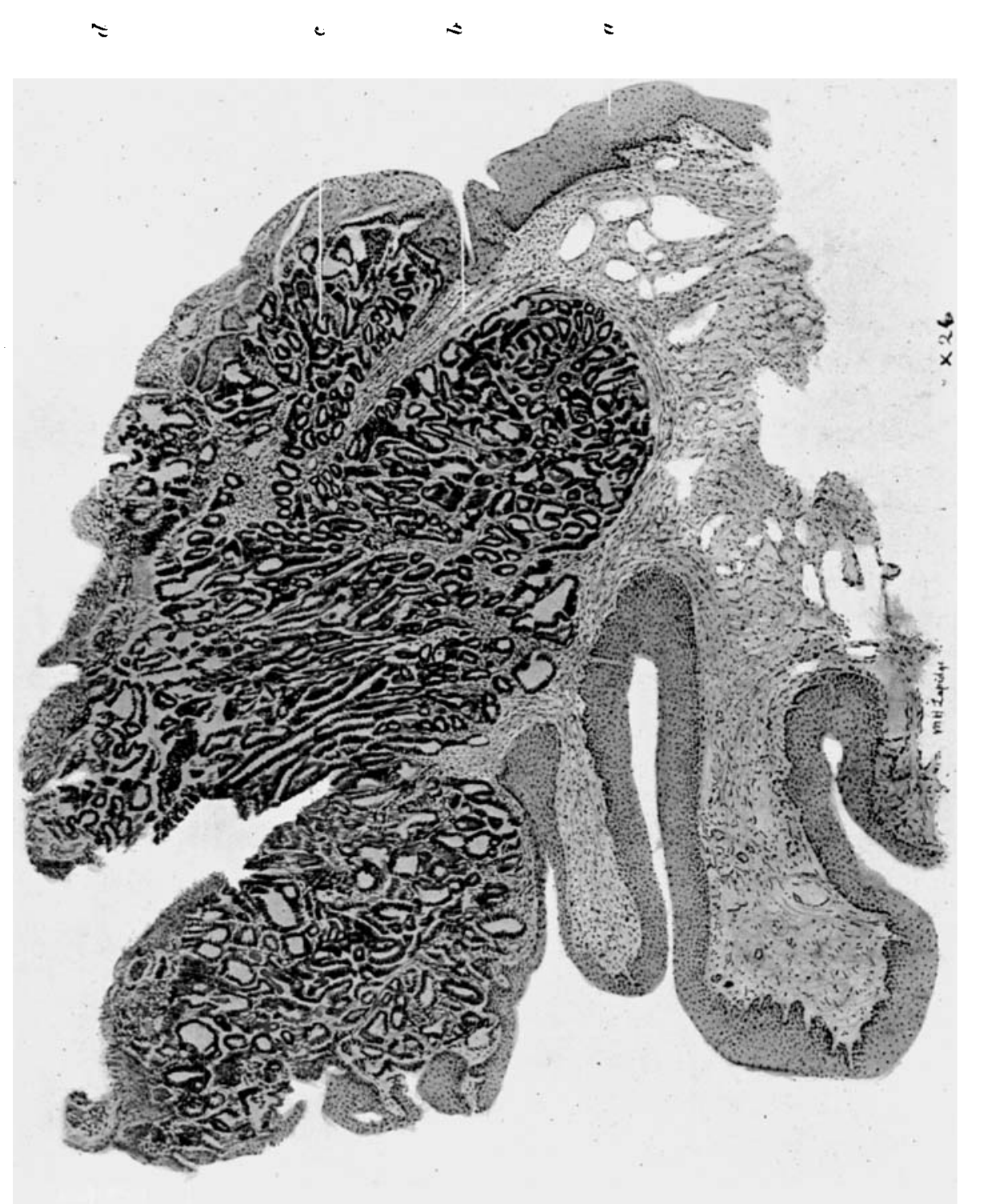

言

范

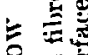

告䓌

$\Xi \underset{\Xi}{\Xi}$

可

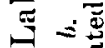

4 응

E

छ

表

4

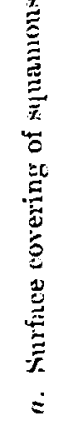




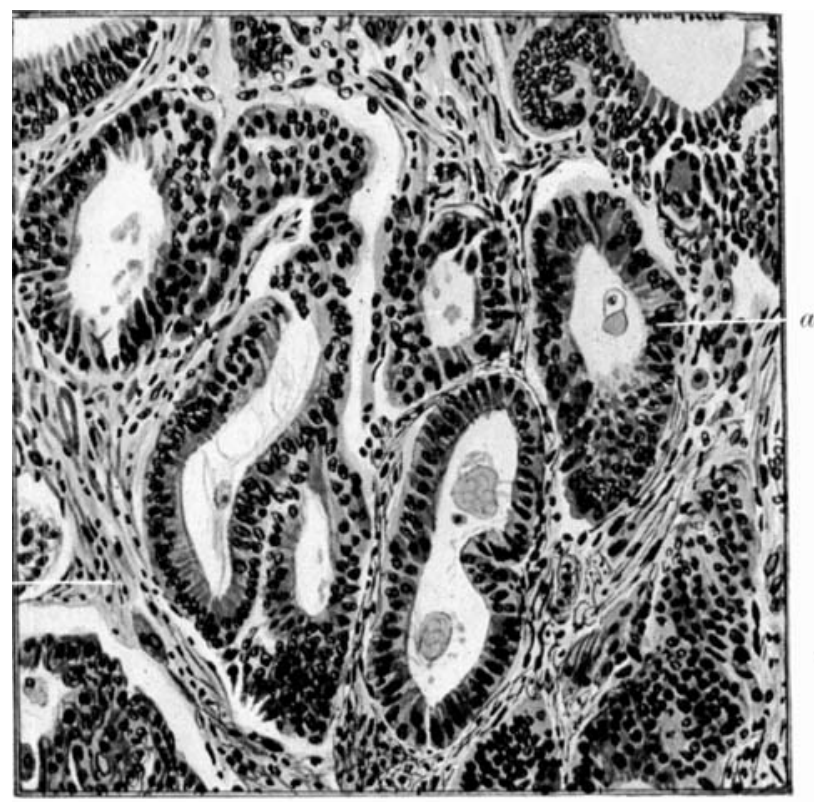

Adenoma of Labium-High Power.

a. Ciludular structure, $b$. Connective tisisue struma. 
tumours presented similar characters; they were hard, the surface was smooth and covered with hair, they could be separated from the skin, and could be moved easily on the deeper structures.

The tumours were removed, and, at the time the case was reported, no recurrence had taken place.

The microscopical appearances were almost identical with those of the tumour I have described.

CASE II. (L. Pick). The patient was a woman, 45 years of age, the subject of arthritis deformans affecting both hands and feet, and also of prolapsus uteri. A single small tumour was situated in the posterior part of the right labium majus and possessed characters very similar to those of the previous case. Its surface was smooth; the growth could be separated from the skin and was freely movable upon the deeper tissues.

The microscopical appearances differed from those in the previous case only in certain minor points: the gland ducts were extremely tortuous; there was no cystic dilatation; there was no definite capsule, and the growth was not lobulated.

CASE 1II. (Schickele). The patient was 35 years of age, and had borne three children. Like the patient in the previous case, she suffered from prolapsus uteri. In the upper part of the right labium minus was a nodule the size of a cherry-stone. It was soft and movable on the underlying structures, but attached to the skin.

The microscopic examination showed that the tumour, which possessed a glandular structure, was composed of epithelial ducts, but the ducts nowhere reached the surface. Immediately beneath the skin were small masses of round cells.

The pathology of adenomatous growths of the vulva is not easy to understand; two theories have been suggested, one by Schickele, the other by Pick. Schickele believes that the tumours arise in connection with abnormal remains of the Wolffian duct. He bases his view upon the resemblance which the growths bear to the kidney, the testicle, and to Wolffian structures in general. To my mind, there are two objections to this theory:-first, the varying situations which the growths occupy; sometimes they are found in the anterior, sometimes in the posterior part of the labium majus, and sometimes in the labium minus. Had they developed in connection with an embryonal structure one would expect them to occupy a more constant position. Secondly, as far as I am aware, no one has ever found Wolffian remains in the labium, and it is almost 
impossible to understand how they could reach that situation, for in animals which possess a persistent Wolffian duct this structure terminates in the vagina, not in the labium.

Pick regards these growths as adenomata arising in connection with sweat-glands, and proposes for them the name "Midradenomata." He bases this opinion upon the resemblance between the growths and the normal sweat-glands, and upon the fact that a few cases of adenomata described in connection with sweat-glands in other parts of the body possess many points in common with these tumours. I have cut sections from five specimens of the labium minus taken from the post mortem room, and have failed to find sweat-glands in any of them; they are, however, sometimes to be found in this situation, and have been described and figured by Clarence. Webster in his study of the nerve-endings in the labia minora.

I have already remarked that when I examined the section I was in grave doubt as to whether the tumour was a secondary nodule of glandular cancer. At that time Pick's paper had not been published, but on reading it later I was interested to find that he had been struck by the close resemblance of these growths to malignant adenomata. "Indeed," he writes, "at first I took them to be metastases of such a growth." Schickele still regards them as probably of a malignant nature.

The case I have recorded has been under observation longer than any of the three previously published, and therefore, after waiting three years, I offer it as a contribution to the natural history of these growths.

\section{REFERENCES.}

1. Pick. "Ueber eine besondere Form nodulärer Adenome der Vulva." Archiv für Gynäkol., 1904, p. 347.

2. Schickele. "Weitere Beiträge zur Lehre mesonephrischen Tumoren." Hegar's Beiträge zur Geburts. und Gynäkol., 1902, Bd. 6, Ht. 3.

3. Webster. "The nerve-endings in the labia minora and clitoris." Edin. Med. Journal, vol. xxrvii., p. 35. 